\title{
Comparison of DDS with two combined chemotherapy regimens for multibacillary leprosy. Results after 3 years of treatment. A prospective randomized multicentre study.
}

\author{
M DIETRICH* \& R WABITSCH \\ Clinical Department, Bernhard-Nocht-Institut, Hamburg, Germany
}

Three hundred and seven lepromatous and borderline lepromatous patients in five participating centres (Freetown, Karachi, Bombay, Madras, Chetput) were randomized to receive one of the three following drug regimens: A, DDS $100 \mathrm{mg} /$ day; B, DDS $100 \mathrm{mg} /$ day + Rifa $600 \mathrm{mg} /$ day; and C, Rifa $600 \mathrm{mg} /$ day + Isoprodian (PTH $175 \mathrm{mg}$, INH $175 \mathrm{mg}$, dapsone $50 \mathrm{mg}$ ), 2 tablets/day. An adjustment was made for patients with less than $60 \mathrm{~kg}$ or more than $80 \mathrm{~kg}$ of body-weight. Criteria for exclusion included active tuberculosis, any other wasting disease, and psychic disorders. Patients who had been on regular or irregular DDS treatment for 3 years or more were excluded. The main characteristics of the study population are shown in Table 1. A complete physical examination, basic laboratory tests (BUN, GOT, GPT, Hb), skin smears and histology were done before treatment and at regular intervals during the 3 years of treatment. Prior to chemotherapy, a DDS-resistance test was performed and in case of DDS resistance the patient was treated as in Group C, but excluded from the study and evaluated separately. Of the 228 patients who are still in the study 10 (Group D) showed to be fully resistant to DDS.

The study design was to treat patients for 3 years and to have a follow-up period of 5 years. We report the results after 3 years of treatment. Of the 180 cases evaluated so far, a total number of 160 showed regression of leprosy while 20 were clinically classified as stable leprosy. There is no progression. The results for the different treatment groups are shown in Figure 1. The bacteriological index (BI) decreases by the same amount in all treatment groups (Figure 2). Histological serial examinations (number of AFB, staining properties, histopathological status) reveal good therapeutic effect with no statistically different response within groups. A leprosy reaction (Type I or II) was seen in $49 \%$, ranging from $48 \%$ in Group A to $64 \%$ in Group D. The three drug regimens were tolerated

* Clinical Study Group: M Dietrich, M Aschhoff, G D Burchard, T Chiang, V Devanbu, S Engelhorn, H Feldmeier, R Ganapati, W Gaus, P P Irudayaraj, J Jayakumar, P Kern, U LaukammJosten, M Peters, R Pfau, J Rangaraj, M Rangaraj, C R Revankar, R Wabitsch. 
Table 1. Characteristics of the three treatment groups

\begin{tabular}{|c|c|c|c|}
\hline Characteristics & DDS & $\mathrm{DDS}+\mathrm{RI}$ & $\mathrm{ISO}+\mathrm{RI}$ \\
\hline Number at admission & 97 & 108 & 101 \\
\hline Male/Female & $79 / 16$ & $85 / 23$ & $82 / 19$ \\
\hline \multicolumn{4}{|l|}{ Age (years) } \\
\hline Mean & $32 \cdot 9$ & $27 \cdot 9$ & $30 \cdot 4$ \\
\hline $\mathrm{BL} / \mathrm{LL}$ & $40 / 57$ & $44 / 64$ & $41 / 60$ \\
\hline BI (mean) & $3 \cdot 6$ & $3 \cdot 5$ & $3 \cdot 8$ \\
\hline Drop-outs & 33 & 25 & 20 \\
\hline Remaining for analysis & 64 & 83 & 81 \\
\hline
\end{tabular}

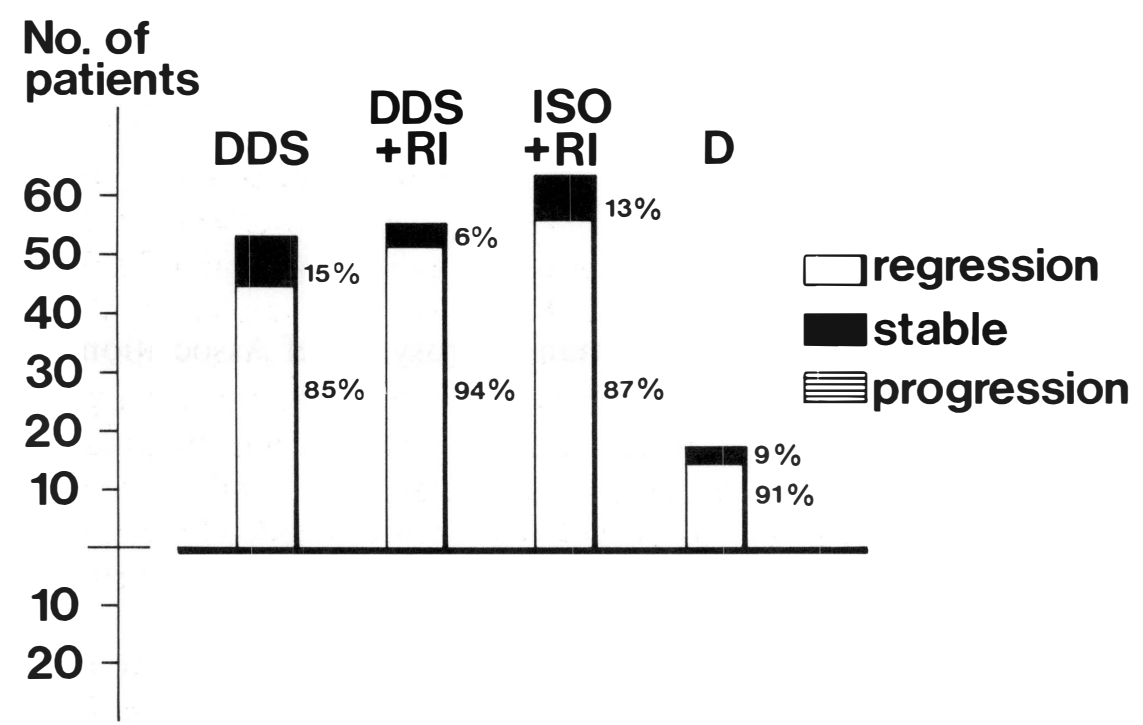

Figure 1. Conclusion of clinical examination after 36 months of treatment

well, and there was no difference in side-effects as judged by GOT, GPT, BUN and haematology serial examinations.

This preliminary evaluation shows no difference in therapeutic response between multidrug and single-drug therapy. Evidence of relapse and/or the development of DDS resistance in the follow-up period will be the important criteria for further recommendations. 


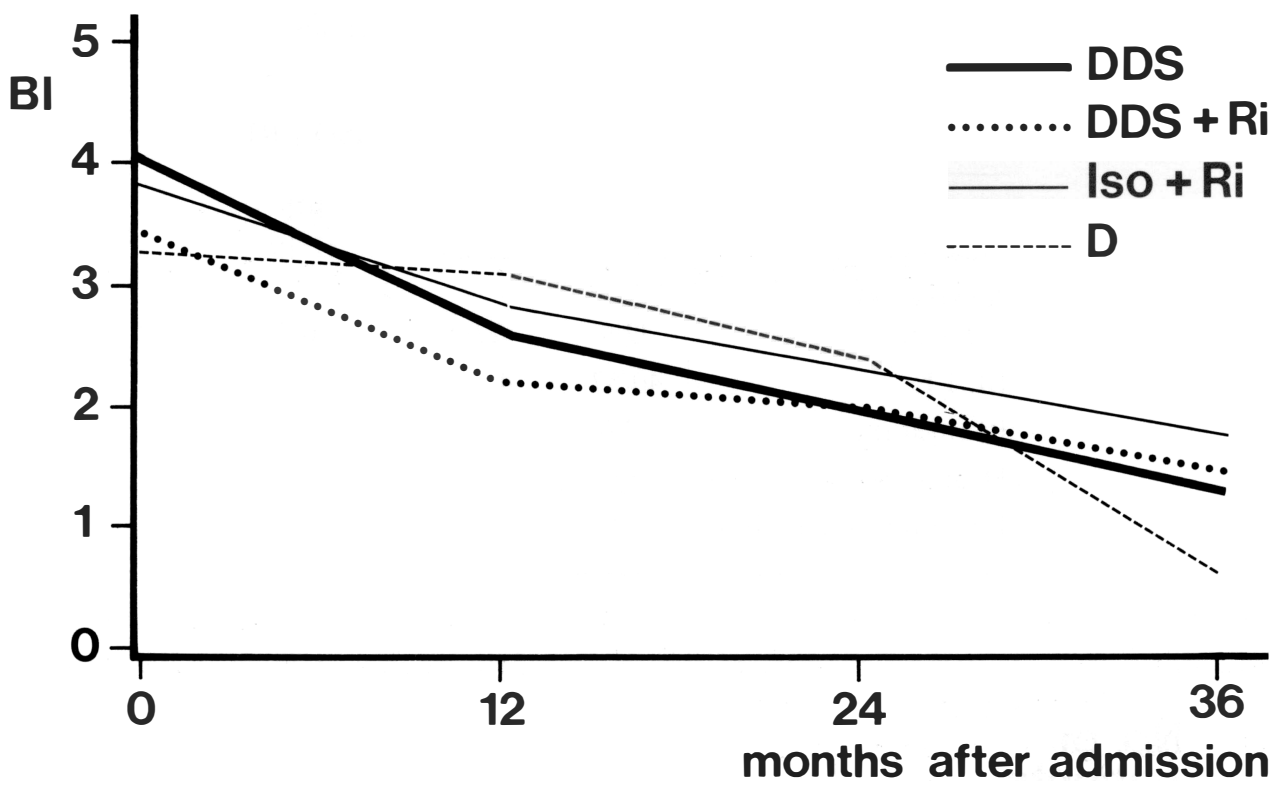

Figure 2. Evolution of the median BI

\section{Acknowledgment}

This study was supported by the German Leprosy Relief Association. 